\title{
Por uma introdução à teoria da multimodalidade: uma abordagem paronâmica para professores de lingua(gem)
}

\author{
Ana Paula Bezerra Matos de Azevedo \\ Escola Estadual José de Alencar \\ anapbma@hotmail.com
}

Maria Clara Maciel de Araújo Ribeiro Universidade Estadual de Montes Claros

mclaramaciel@hotmail.com

\section{Resumo}

Este estudo propõe-se a apresentar a Teoria da Multimodalidade (TM) em uma abordagem panorâmica, focalizando-a tanto em sua constituição teórica quanto em seus desdobramentos educacionais. Assim, pretende-se oferecer um apanhado teórico-conceitual capaz de situar o professor de lingua(gem) nos estudos contemporâneos que discutem produção de sentidos em textos multimodais. Para tanto, inicialmente se discorre sobre os subsídios teóricos que possibilitaram a emergência da TM e se selecionam subcategorias capazes de ilustrar a potencialidade de compreensão de imagens proporcionada pela teoria, a saber: i) na estrutura representacional: participantes representados e interativos; ii) no significado social: contato e distância social; e iii) no significado composicional: valor da informação. Ao fim, conclui-se que a TM representa um importante suporte para o professor de lingua(gem) pensar, discutir e ensinar uma atividade eminentemente contemporânea, que deriva sobretudo do advento das tecnologias digitais - a leitura multimodal.

Palavras-chave: Teoria da Multimodalidade. Leitura. Professor de lingua(gem).

\section{Abstract}

This study presents the Multimodality Theory (TM) in a panoramic approach, focussing it both on its theoretical constitution as well as on its educational developments. Thus, it is intended to offer a theoretical-conceptual approach capable of situating language teachers in the contemporary studies that discuss production of meaning in multimodal texts. Therefore, initially, we discuss 
theoretical subsidies that enabled the emergence of TM and select subcategories capable of illustrating the potential of image comprehension provided by the theory, namely: i) in the representational structure: represented and interactive participants; ii) in the social meaning: contact and social distance and iii) in the compositional meaning: information value. It is concluded that the TM represents an important support for the Portuguese teacher to think, discuss and teach an eminently contemporary activity, which derives mainly from the advent of digital technologies: multimodal reading.

Keywords: Multimodality Theory. Reading. Portuguese teacher.

\section{Introdução}

Nos últimos anos, a Linguística Textual precisou alargar seu escopo para semioses que vão além da verbal. Hoje, é difícil pensar em meios de expressão exclusivamente verbais, pois além das palavras significamos imagens, gestos, sons, diagramações e cores, por exemplo. Assim, o conceito atual de texto já não se limita à linguagem verbal, mas se estende a uma gama de possibilidades semióticas que se articulam e complementam.

$\mathrm{Na}$ chamada era da informação e da tecnologia digital, os modos de produzir sentido transformaram-se drasticamente. Por meio da tecnologia, novos elementos e novas formas de combiná-los tornaram a comunicação um mar muito mais profundo e vasto que outrora - e é preciso ensinar jovens marinheiros a navegar com segurança e confiança nessas águas.

Como sustentam Prediger e Kersch (2013), parece que a velha configuração do papel branco, com letreiro padrão e linearmente organizado, ao lado de (talvez) uma imagem ilustrativa em preto e branco, tem perdido espaço para novos formatos, cores, texturas, movimentos e organização do espaço que, definitivamente, fazem parte do atual processo de expressão e compreensão de textos.

É diante disso que Rojo (2012) considera que a demanda por multiletramentos deriva do recente fenômeno da multimodalidade dos textos contemporâneos, que exigem habilidades específicas e distintas para produzir e compreender significativamente cada um dos modos que compõem um texto. 
Ler, assim, torna-se uma tarefa cada vez mais complexa, pois os elementos da composição se tornam cada dia mais variados, sofisticados e multiarticulados, inegáveis frutos da criatividade humana aliada à disponibilidade de recursos digitais de nossos tempos.

Apesar dessas transformações, constata-se que reflexões sobre a multimodalidade ainda não chegaram, de fato, à escola, pois o letramento da letra ainda tem uma dimensão quase totalizadora na sala de aula tradicional. Muitos professores alegam não ter propriedade para abordar o texto na dimensão ampla dos estudos atuais pelo fato de não terem tido, em suas formações iniciais, discussões sobre a multimodalidade, como relatam três professoras do norte de Minas Gerais: (1) exploro nos textos multimodais, na maioria das vezes, apenas o texto verbal; (2) peço que eles leiam os textos, mas confesso que não tenho segurança para trabalhar com textos $e$ imagens ao mesmo tempo, pois nunca estudei isso na faculdade; (3) não tenho segurança para trabalhar texto e imagem e acabo deixando a imagem de lado. $O$ que eu sei é intuitivo e prefiro não arriscar.

Os depoimentos anteriores atestam pelo menos duas coisas: primeiro, que professores formados antes do boom tecnológico dos últimos tempos certamente não participaram de discussões relativas à multimodalidade. Segundo, que professores consideram o estudo formal uma condição para a atuação responsável.

Logo, muitos professores não exploraram a multimodalidade que constitui todo texto por não se sentirem seguros para fazê-lo, e tal insegurança certamente advém da falta de referencial teórico sobre o tema.

Visando principalmente contribuir para a formação do professor de lingua(gem), este artigo apresenta a Teoria da Multimodalidade (TM) em uma abordagem panorâmica, focalizando a Gramática do Design Visual (KRESS; VAN LEEUWEN) tanto em sua constituição teórica quanto em seus desdobramentos educacionais. Para tanto, a partir dos estudos de Kress e van Leewen (2006) apresentamos inicialmente a relação da TM com a Linguística Sistêmico-Funcional e a Semiótica Social, visualizando as metafunções hallidianas na Gramática do Design Visual (GDV). Em seguida, selecionam-se categorias para ilustrar a potencialidade da leitura proporcionada pela GDV e, ao fim, reflete-se sobre as práticas de leitura multimodal na escola. 
Nossa intenção, com este texto, é contribuir com a formação de professores de línguas materna e estrangeiras que busquem suporte teórico para pensar a multimodalidade junto a estudantes da Educação Básica.

\section{A Linguística Sistêmico-Funcional e a Semiótica Social: subsídios para a Teoria da Multimodalidade}

Inúmeros autores apontam a Linguística Sistêmico-Funcional (LSF) e a Semiótica Social (SS) como escolas que influenciaram decisivamente as bases da TM (PIMENTA, 2008; DIONÍSIO, 2011; VIEIRA; SILVESTRE, 2015).

A LSF é uma perspectiva de análise linguística australiana desenvolvida pelo pesquisador Michael Halliday no fim da década de 1980. Grosso modo, é possível dizer que ela se sustenta na ideia de que, como usuários da língua, produzimos textos condicionados por sistemas socialmente instituídos, assim como subordinados aos contextos sociais e culturais.

Halliday (2004) explica a linguagem como um recurso capaz de construir significados motivados para exercer funções em contextos sociais específicos. O autor considera que os usos da língua, através de gerações, é que conferem forma ao sistema, não o contrário. Assim, as dimensões sociais e culturais são altamente relevantes para determinar escolhas e entender os vários modos semióticos existentes.

Nessa perspectiva, Halliday (2004) defende que todas as línguas se organizam em torno de dois significados principais: o ideacional (reflexivo) e o interpessoal (ativo). O primeiro destaca a importância de entender o ambiente (ideacional) e o segundo de se influir sobre as pessoas (interpessoal). Associado aos primeiros está o significado textual, capaz de organizar e conferir relevância a eles.

Assim, Halliday (2004) identifica, por meio desses componentes, o caráter multifuncional da linguagem, apontando para a existência de três trabalhos semióticos, ou metafunções, que se realizam simultaneamente: a ideacional, a interpessoal e a textual.

Para o autor, a primeira metafunção é responsável por construir as experiências humanas, nomeando-as e representando-as em categorias. A segunda desempenha distintos tipos de relação entre os 
participantes, enquanto a terceira organiza o fluxo discursivo em seus movimentos sucessivos de interação, mantendo a coesão textual.

Assim, Dionísio; Vasconcelos e Souza (2014, p. 51) asseguram que, por esse prisma, uma oração é "a realização simultânea de três significados": uma representação, uma troca e uma mensagem.

A SS, por sua vez, estuda a comunicação humana por meio de aspectos amplos que ultrapassam a comunicação verbal. Voltada para o "estudo geral da semiose, isto é, dos processos e efeitos da produção e reprodução, recepção e circulação de significado em todas as formas, usadas por todos os tipos de agentes de comunicação" (HODGE; KRESS, 1988, p. 26), a Semiótica Social é, pois, uma teoria que comunga com os trabalhos relacionados à LSF.

Pode-se dizer que o trabalho de Hodge e Kress, intitulado Social Semiotics (1988), é o marco inicial dos estudos relacionados à Sociossemiótica, "ciência que se encarrega da análise dos signos na sociedade, cuja função principal é o estudo da troca de mensagens, ou seja, da comunicação dentro de um contexto social; nessa teoria, as diversas formas de representação são denominadas modos semióticos", como assevera Pimenta (2008, p. 4, grifos nossos). Dessa maneira, "ações como falar, ler, escrever, gesticular, desenhar, são meios dos quais o homem se utiliza para se comunicar com os demais, produzindo significados sociais" (HODGE; KRESS, 1988, p. 26).

Buscando respaldo na LSF e na SS, Kress e van Leeuwen propõem um aprofundamento nos estudos referentes aos textos visuais e apresentam a Teoria da Multimodalidade (TM), por meio de uma Gramática do Design Visual (2006), como forma de atender às necessidades de se desenvolver métodos de estudo que analisem as imagens como modos semióticos carregados de sentido.

A LSF e a SS permitem-nos compreender que é preciso estender os processos interpretativos a uma "vasta gama de modos comunicacionais e representacionais utilizados numa mesma cultura" (PIMENTA, 2007, p. 4). Vale destacar que este é um aspecto relevante enfatizado pela SS e que se estende para a TM.

Consoante Pimenta (2007), Jewit e Oyama (2001) salientam que a natureza dos recursos semióticos são "produtos de histórias culturais e recursos cognitivos que usamos para criar significados na produção e interpretação de mensagens visuais e de outros tipos" (JEWIT; OYAMA, 2001 apud PINHEIRO, 2007, p. 18). 
Assim, a TM assume que modos semióticos são moldados tanto pela cultura quanto por funções sociais, culturais e ideológicas, de modo que é possível dizer que a Multimodalidade unifica teorias semióticas e críticas em prol de um princípio de leitura capaz de voltarse, ao mesmo tempo, para as determinações da cultura e as escolhas representacionais.

Percebe-se, assim, que os atos comunicacionais são socialmente construídos por meio de escolhas de modos semióticos mais aceitáveis, e seus significados dependem do contexto em que são produzidos e das motivações e dos objetivos de quem e para quem os produz.

Por essa via, Pimenta (2006) afirma que, para a TM, eventos discursivos são constituídos por pequenas partes de significados que, juntos, compõem uma determinada paisagem semiótica.

Sendo assim, quando falamos em textos multimodais, pensamos no fato de que os textos multissemióticos, como o anúncio publicitário, a charge e a propaganda social, envolvem um complexo jogo de elementos gráficos, como escrita, cor, imagens, enquadramento, diagramação, espaço entre imagens e texto verbal, escolhas lexicais, predominância para um ou outro modo semiótico e, eventualmente, elementos sonoros e imagens com movimentos, de acordo com sua finalidade comunicativa.

Enquanto a análise semiótica na LSF se realiza operando, ao mesmo tempo, por meio das metafunções ideacional, interpessoal e textual, na TM, Kress e van Leeuwen recontextualizam essa perspectiva funcional da linguagem para descrever o modo semiótico visual.

Nesse contexto, na GDV, as metafunções da LSF equivalemse, respectivamente, a estruturas representacionais, significados interacionais e significados composicionais, aspectos que, entre outros, serão explicitados na próxima seção.

\section{As metafunções de Halliday sob a ótica da Gramática do Design Visual}

Vimos que Kress e van Leeuwen (2006) apregoam que imagens são construtos de significado dotados de estruturas sintáticas e 
significados próprios e que, por isso, necessitam ser lidas e interpretadas sistematicamente, como os textos verbais o são. Portanto, a linguagem visual, como a verbal, possui uma sintaxe própria, o que possibilita análises específicas a essa composição.

Assim, o objetivo da gramática desses autores é unir "as principais estruturas composicionais que têm se tornado convenções ao longo da história da semiótica visual e analisar como elas são usadas pelos produtores de imagem contemporâneos para produzir sentido", concebendo o contexto, os envolvidos na interação e as atividades discursivas como um processo dinâmico e de múltiplas articulações (KRESS; VAN LEEUWEN, 2006, p. 1, tradução nossa).

Nessa perspectiva, é possível afirmar que o estudo das formas se subordina e se vincula ao estudo dos significados, numa espécie de "sintaxe visual" que equaciona valor formal e valor semântico para a explicação de regularidades encontradas em estruturas visuais produzidas na cultura ocidental.

Como dito, essa concepção funcional baseia-se nas ideias de Halliday (2004), formuladas originalmente para a linguagem verbal por meio das metafunções ideacional, interpessoal e textual e reconfiguradas para o modo semiótico visual por meio da estrutura representacional e dos significados interacional e composicional, respectivamente.

Assim, na GDV, a estrutura representacional, como a sua correspondente linguística, a metafunção ideacional (LSF), expressa a experiência e a habilidade dos participantes (representados e interativos) representarem e interpretarem o mundo. Tal estrutura leva em consideração a representação dos seres, dos lugares e das coisas no processo de interação, que acontece por meio de duas estruturas: as narrativas (que encerram processos de ação) e as conceituais (com processos estáticos) (KRESS; VAN LEEUWEN, 2006, p. 73).

$O$ primeiro tipo de representação (narrativa) pode ser entendido em termos de processos de ação, reação, verbal, mental, conversão e simbolismo geométrico. Nesse caso, as estruturas narrativas caracterizam-se pela dinamicidade das ações praticadas pelos participantes, as quais podem ser descritas visualmente por meio de vetores ou linhas. O segundo (conceitual) é subdividido em formas analíticas, classificatórias e simbólicas e sua análise se dá em termos de processos de descrição, estado e identidade. Nesse caso, as 
estruturas conceituais caracterizam-se pela estaticidade, pois são desprovidas de relações por meio de vetores, em que os participantes são representados significando algo sobre o qual atribuímos características, identidades ou valores.

$\mathrm{Na}$ GDV, o significado interacional, que corresponde à metafunção interpessoal (LSF), expressa a relação estabelecida entre os interlocutores (chamados participantes representados e interativos), que, ao desempenharem suas funções, criam possíveis significados, tendo como embasamento o contexto social do qual fazem parte. Ao conhecer esses princípios, os alunos terão a possibilidade de perceber que aspectos como a direção do olhar, a distância social existente entre os participantes representados e os interativos na composição, por exemplo, são escolhas que implicam diretamente a constituição do significado que se quer alcançar. Tais escolhas constroem relações por meio de realizações visuais como categorias de contato, distância social, atitude e modalidade (KRESS; VAN LEEUWEN, 2006).

Quanto ao significado composicional, correspondente à metafunção textual (LSF), este expressa, por sua vez, a relação e a disposição que os elementos visuais ocupam na composição visual para a construção de sentidos, bem como a relação que esses elementos mantêm com a situação em que são usados. Nas imagens, essa dimensão é analisada por meio de aspectos como valor de informação, saliência e moldura. Para os objetivos desta pesquisa, limitar-nos-emos apenas ao primeiro aspecto dessa descrição (valor de informação) (KRESS; VAN LEEUWEN, 2006). ${ }^{1}$

Com base na organização da estrutura composicional, é possível analisar a realização dos significados representacional $e$ interacional num todo significativo, que geram uma composição coerente e harmônica (KRESS; VAN LEEUWEN, 2006). Para esses autores, o emprego desses significados da composição da imagem

${ }^{1}$ Esclarecemos que a teoria aqui apresentada é meramente ilustrativa, uma vez que a natureza aplicada desta pesquisa exige de nós uma postura mais pragmática, diante dos problemas de ensino da escola, do que teórica. Isso não significa que desconsideramos a importância da teoria, mas tão somente que compreendemos que enquanto os fazeres teóricos se alargam, na área da educação, os aplicados encolhem-se, razão que direciona nossa prioridade ao pragmatismo da sala de aula. 
estende-se também a textos multissemióticos (não apenas à imagem). Para Pinheiro (2007, p. 57), “a integração entre diferentes códigos semióticos é realizada por um código maior, o qual, por meio de suas regras e significados, confere unidade semiótica e coerência ao texto multimodal [...]". Assim, na visão do autor, "o código integracional em atuação é o código da composição espacial” (p. 57).

É de se pontuar que trabalhar na escola questões relacionadas à organização dos componentes visuais possibilita o desenvolvimento crítico-leitor dos alunos, visto que os sujeitos passam a considerar o valor semântico da junção imagem-texto, deixando de perceber o modo visual como adorno. Isso aponta para a importância de o professor de lingua(gem) se apropriar dessa perspectiva teórica para levar seus princípios para a sala de aula, modernizando as práticas de leitura e escrita escolar.

\section{1 Algumas categorias da GDV}

Dando continuidade à proposta de apresentar e discutir a TM pensando prioritariamente nos professores e nos estudantes que a desconhecem, selecionamos entre uma e duas categorias de cada metafunção para ilustrar, neste trabalho, como se pode proceder, a partir da TM, para ler sistematicamente textos multimodais.

Nossa proposta nesta seção não é discutir a fundo cada categoria, mas sim apresentá-las por meio de exemplificações compreensivas, para que se possa vislumbrar o potencial das análises realizadas com base no suporte teórico. Para tanto, partiremos tanto da GVD, de Kress e van Leuween, quanto de autores que o traduzem e ilustram, dadas as necessidades didáticas desta pesquisa. Os exemplos apresentados a seguir foram extraídos de trabalhos sobre a TM e versarão sobre as seguintes categorias: i) participantes representados e interativos (estrutura representacional); ii) contato e distância social (significado interacional); e iii) valor da informação (significado composicional). 


\subsection{Estrutura representacional: participantes representados $\mathrm{e}$ interativos}

Nos textos multimodais, os elementos presentes na composição recebem classificações específicas de acordo com sua função. Como visto, a teoria do processo comunicacional distingue dois tipos de participantes, que interagem por meio de imagens: os participantes representados e os participantes interativos. Os primeiros são mostrados na composição visual, enquanto os segundos são aqueles que produzem ou consomem as imagens.

Assim, pessoas, lugares e coisas, inclusive as abstratas, por exemplo, são chamadas de participantes representados, pois têm a função de representar o objeto da comunicação (KRESS; VAN LEEUWEN, 2006). Sobre eles fala-se, escreve-se ou produz-se imagens.

Os participantes interativos, por sua vez, são aqueles que agem no momento da comunicação, falando e ouvindo, escrevendo e lendo, criando ou vendo imagens (KRESS; VAN LEEUWEN, 2006). Nesse contexto, os participantes têm a função de agir e interagir com o texto. É o caso, por exemplo, da Figura 1.

Figura 1. Exemplo de participantes representados e interativos

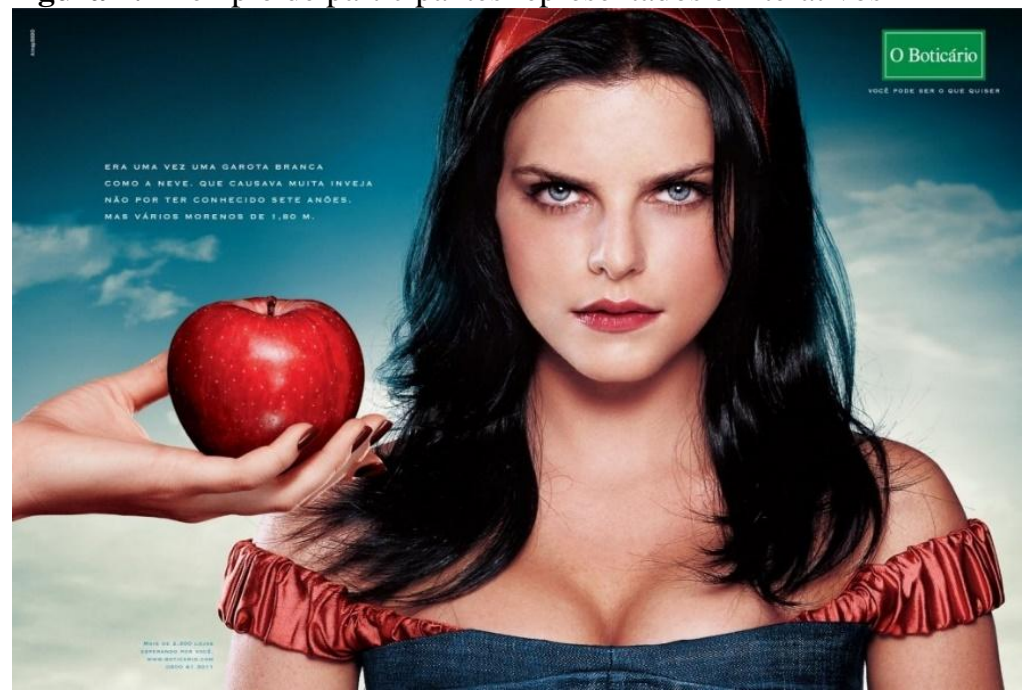

Fonte: PETERMAN (2006, p. 547) 
Sem entrarmos em maiores detalhes, podemos afirmar que o anúncio publicitário da marca $O$ Boticário compõe-se pelos participantes representados, uma jovem de pele branca e cabelos pretos, a mão cortada pela moldura e uma maçã. Como participantes interativos temos a participante representada (com olhar de demanda) e os leitores, possíveis consumidores dos produtos da marca anunciada.

\subsection{Significado interacional: contato e distância social}

O significado interacional diz respeito ao grau de interação entre os elementos da composição (participantes representados) e o leitor (participantes interativos). Neste estudo, daremos prioridade às categorias contato e distância social, como se vê a seguir.

\subsubsection{Contato: olhar de demanda ou de oferta}

$\mathrm{Na}$ TM, a relação entre os participantes da interação pode ser caracterizada, entre outras formas, pelo direcionamento do olhar.

De acordo com Kress e van Leeuwen (2006), se o olhar é voltado diretamente ao participante interativo (leitor/espectador), temse o olhar de demanda. Neste caso, há um maior contato, uma maior interação e uma forte conexão entre os envolvidos, mesmo que seja apenas no nível imaginário, "exigindo" do leitor uma atitude responsiva, como demonstra a Figura 2.

Observa-se que a participante representada (elemento da composição) olha fixa e diretamente para o participante interativo (leitor), o que reforça o caráter de intimidade e proximidade entre os participantes, pois convida o observador a responder ao apelo da compra, compartilhando/adquirindo o produto, neste caso, a cerveja Devassa, como discutem Simões e Macedo (2013). Trata-se de um aspecto bastante explorado em anúncios publicitários contemporâneos. 
Figura 2. Exemplo de direcionamento do olhar (demanda)

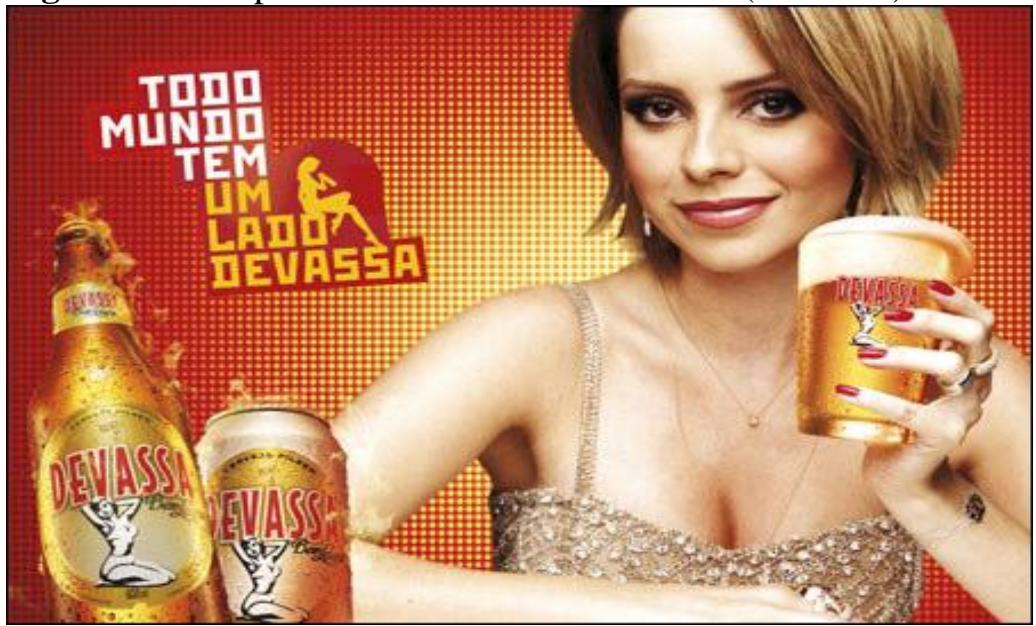

Fonte: SIMÕES; MACEDO (2013, p. 13)

Entretanto, se o olhar não se direciona diretamente ao leitor, tem-se o olhar de oferta (KRESS; VAN LEEUWEN, 2006). Neste caso, nenhum contato é estabelecido. O participante representado é oferecido ao participante interativo como item de informação ou contemplação, de maneira impessoal e mais distante que na primeira opção. Assim, a relação estabelecida é de menor interação.

É o que acontece na Figura 3, em que uma moça toca um instrumento com o olhar desviado da câmera, oferecendo-se como objeto de contemplação aos participantes interativos.

Ainda em relação ao significado interacional, segundo a TM a distância entre os participantes representados e os participantes interativos pode também se traduzir numa relação fictícia de maior ou menor distância social entre eles. 
Figura 3. Exemplo de direcionamento do olhar (oferta)

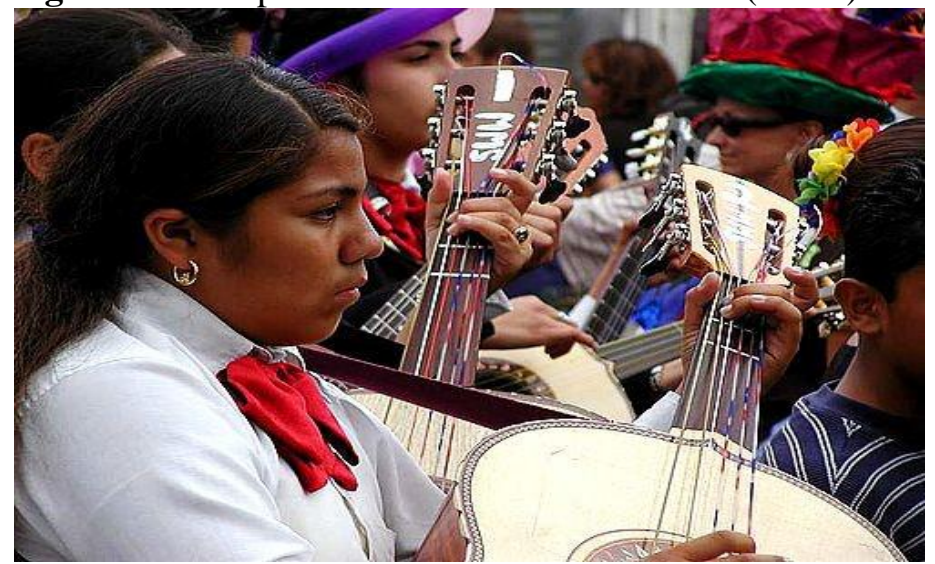

Fonte: BEZERRA; HEBERLE; NASCIMENTO (2011, p. 543.)

\subsubsection{Distância social: plano fechado, plano médio ou plano aberto}

Kress e van Leeuwen (2006) apresentam uma infinidade de tipos de enquadramento, entretanto para fins desta pesquisa trataremos aqui de apenas três: plano fechado (relação social próxima), plano médio (relação social média) e plano aberto (relação social distante).

É relevante destacar que o enquadramento dos participantes na composição determina a relação social imaginária entre eles (distinção entre íntimos, amigos, conhecidos, estranhos).

Nessa perspectiva, se retratados cabeça e ombros, tem-se o plano fechado, o que significa dizer que a distância é próxima, familiar, e a relação com o leitor, neste caso, é íntimo-pessoal (KRESS; VAN LEEUWEN, 2006).

É o que acontece na Figura 4 cujo texto é um anúncio de um produto de beleza feminino, que parece tentar simular a prática de testemunho e indicação de produtos de beleza entre amigas. Assim, para representar uma distância social mínima entre participante representado e participante interativo utiliza-se o close, apresentando um rosto em detalhe e diminuindo a distância social entre os participantes (PETERMANN, 2006). 
Introdução à teoria da multimodalidade...

Figura 4. Exemplo de plano fechado

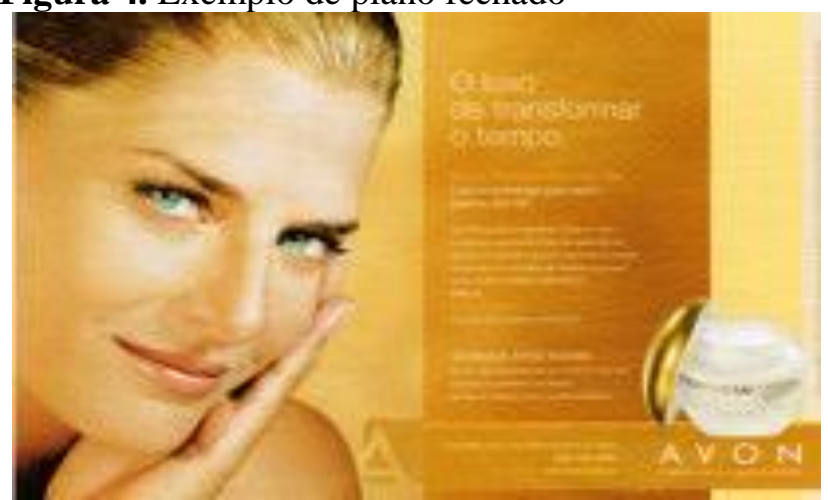

Fonte: PETTERMAN (2006, p. 67)

Na Figura 5 a seguir, uma propaganda social de prevenção da Aids, o participante representado é uma atriz conhecida do público e enquadra-se num plano médio, uma vez que é retratada até a região da cintura.

Figura 5. Exemplo de plano médio

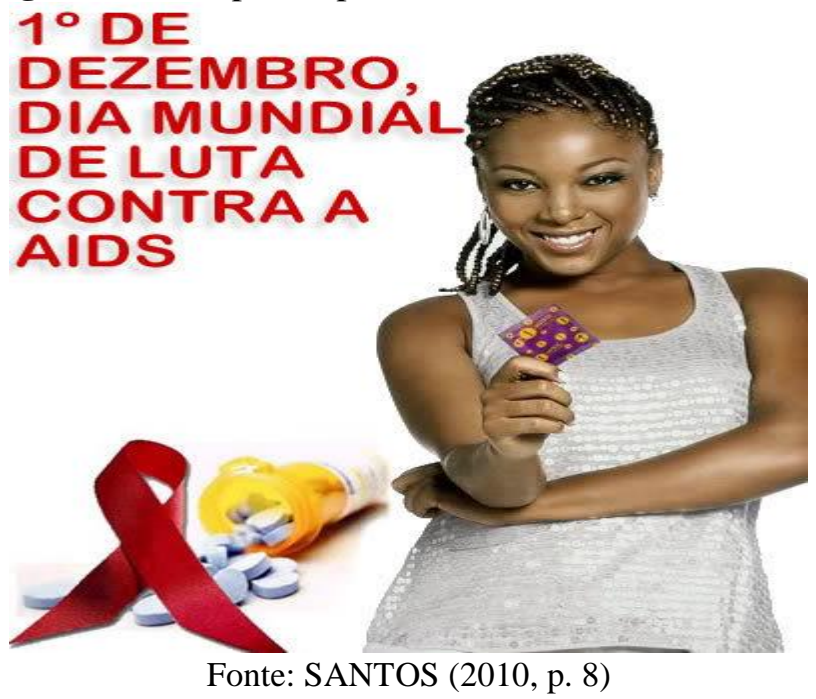


Nessa figura, a distância social configura-se como uma relação social média entre os envolvidos na interação. Desse modo, o participante é representado numa distância intermediária em relação aos observadores, porém ocupando o primeiro plano da imagem, o que cria uma relação um pouco mais próxima (poder-se ia dizer, de amizade) com o participante interativo, intencionalidade advinda, talvez, do produto anunciado (SANTOS, 2010).

$\mathrm{Na}$ Figura 6, a seguir, o conceito de distância social determinará uma relação impessoal entre os participantes, considerada distante por retratar o corpo inteiro do participante representado, em um enquadramento do tipo aberto. Isso confere uma relação de impessoalidade entre o participante representado e o interativo.

A participante representada, a artista Paris Hilton, é apresentada de corpo inteiro, o que configura um distanciamento entre o participante representado e o interativo, ou seja, o possível consumidor da cerveja, que admira a participante representada (figura bastante famosa) a partir de um plano que os distancia (SIMÕES; MACEDO, 2013).

Figura 6. Exemplo de plano aberto

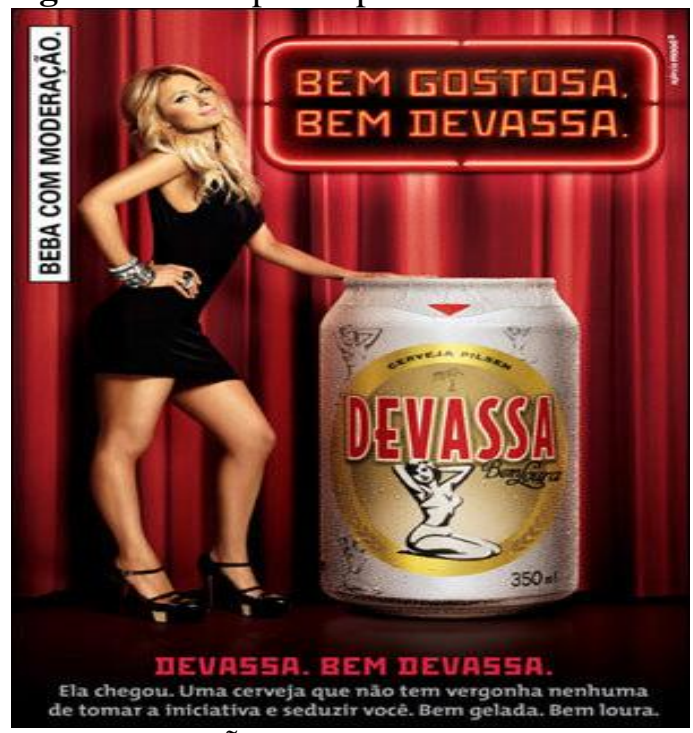

Fonte: SIMÕES; MACEDO (2013, p. 6) 


\section{3 Significado composicional}

\subsubsection{Valor da informação}

A seguir serão apresentadas categorias relacionadas ao valor da informação, aspecto relacionado ao local ou à zona ocupada pelos elementos da composição. Assim, torna-se relevante observar os lugares ocupados pelos participantes representados, uma vez que a disposição espacial (se o elemento está à esquerda ou à direita, no topo ou na base, no centro ou nas margens) não é casual ou desprovida de significado, ao contrário, reflete decisivamente na produção de sentidos.

Vieira e Silvestre (2015) chamam a atenção para o fato de tais elementos não poderem ser analisados em etapas ou de maneira desconectada de outros aspectos da produção de sentidos. É fundamental levar em conta, conjuntamente ou até mesmo primeiramente, aspectos do mundo exterior (práticas e contextos culturais/sociais) para relacioná-los ao significado do lugar/zona ocupada pelo elemento da composição.

De acordo com Kress e van Leuween (2006), tais lugares denotam valores informacionais específicos. Desse modo, considerando a relação dos elementos de composição no eixo horizontal (zonas esquerda/direita), teremos, conforme Kress e van Leeuwen (2006), o valor do Dado e do Novo, respectivamente. Em relação ao eixo vertical (topo/base), veremos os significados da projeção do Ideal e do Real; enquanto a relação Centro/Margem demonstra o ponto de atenção ou subordinação. Tais categorias serão brevemente exemplificadas a seguir.

\subsubsection{O dado e o novo}

Considerando o eixo horizontal, a informação dada, segundo Kress e van Leeuwen (2006), costuma posicionar-se do lado esquerdo da imagem, significando que se trata de uma informação já conhecida ou familiar, pertencente, portanto, à cultura do participante interativo. Nesse sentido, se determinado elemento se posicionar à esquerda da imagem, entende-se que o elemento é Dado. 
Por sua vez, a informação nova é aquela que ainda está por ser dita ou mostrada, segundo os autores, sendo posicionada do lado direito da composição visual. Esse elemento é, portanto, ainda desconhecido e digno de atenção do leitor, passível de questionamento e, por isso, merecedor de uma atenção especial. Tais categorias podem ser apreendidas no anúncio a seguir.

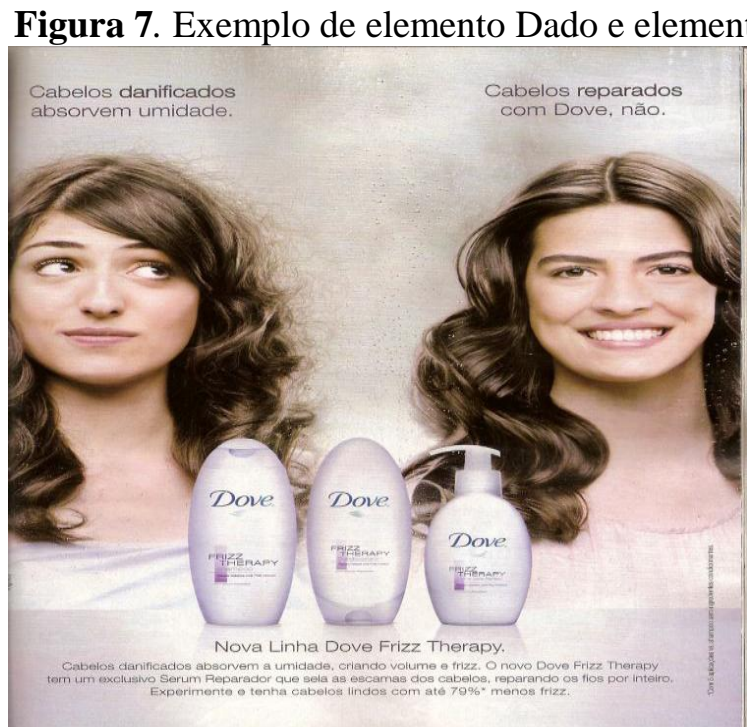

Fonte: SANTOS (2010, p. 11)

De acordo com Santos (2010), no anúncio acima vemos o participante representado mostrado em dois momentos, ocupando ângulos horizontais. Do lado esquerdo, destaca-se o olhar de oferta (projetado aos cabelos desalinhados do participante). A expressão facial demonstra desconforto e insatisfação, sentimento confirmado pelo letreiro superior ("cabelos danificados absorvem umidade"), estado possivelmente conhecido por muitos participantes interativos.

Do lado direito, ao contrário, destaca-se uma nova condição: com cabelos alinhados e expressão facial de contentamento, o participante representado lança um olhar de demanda para os participantes interativos, convidando-os a experimentar daquela sensação. 
O contraponto das duas figuras demonstra uma precisa articulação na utilização dos modos semióticos. Tem-se, no centro da página, a figura dos produtos, colocados como atores responsáveis pela mudança de estado do participante representado, como destaca Santos (2010).

\subsubsection{O real e o ideal}

Considerando o eixo vertical, o elemento disposto no topo da composição significa, segundo Kress e van Leeuwen (2006), o Ideal, sendo, portanto, em termos hierárquicos, uma informação mais importante, dominante e idealizada do que as demais.

Por conseguinte, o elemento situado na base é considerado dominante, por trazer uma informação mais específica e detalhada, significando o elemento Real da composição.

Porquanto, se posicionado no ângulo superior, o elemento é Ideal (sonho), imaginável, promessa a ser alcançada pelo observador. No entanto, se posicionar-se no ângulo inferior, o elemento é Real (realidade), ou seja, subordinado ao primeiro e comum para o observador, de acordo com os autores.

$\mathrm{Na}$ Figura 8 a seguir, tem-se a capa do filme Titanic. Pode-se perceber que os protagonistas do filme estão localizados no topo, enquanto o navio e as informações verbais estão situados na base da composição visual, reservada para as informações mais detalhadas e reais do filme.

Nessa perspectiva, a base, o Real, traz informações concretas e percebidas como verdadeiras (subordinadas à trama principal, a história de amor dos personagens), enquanto o topo, o Ideal, traz a imagem idealizada dos personagens protagonistas do filme. 
Figura 8. Exemplo do Ideal e do Real

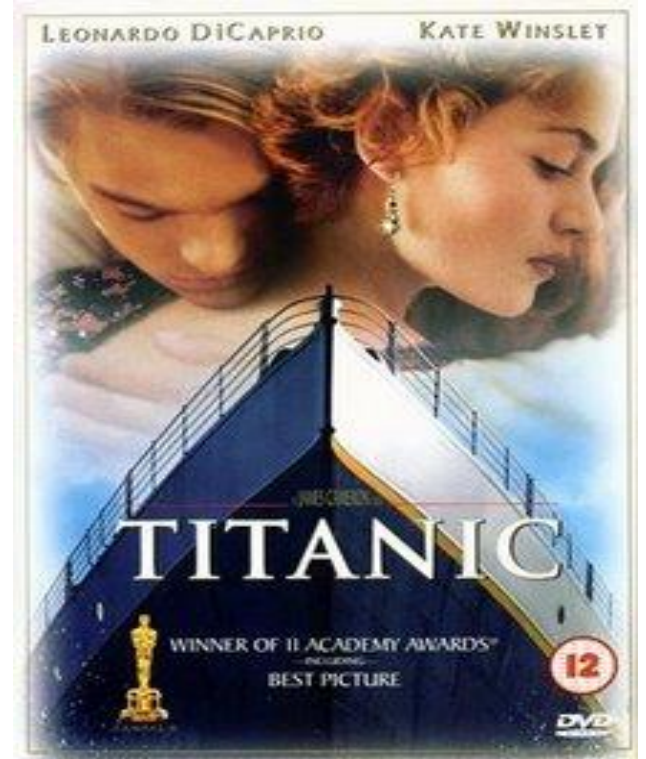

Fonte: <https://frankcastiglione.wordpress.com/2010/07/15/fanatismos/>. Acesso em: 21 out. 2014

\subsection{4 $O$ centro e a margem}

Como dito anteriormente, o valor semântico dos elementos que compõem o texto multimodal sofre variação de acordo com sua disposição no espaço. Sendo assim, a disposição do elemento na posição central da composição significa ser aquele o elemento responsável por veicular o núcleo da informação, considerado o Centro (centro de atenção) (KRESS; VAN LEEUWEN, 2006).

Por sua vez, os elementos posicionados ao redor da área central significam Margens (KRESS; VAN LEEUWEN, 2006) e, de alguma maneira, apresentam relação de subordinação, suporte e dependência ao elemento central, podendo significar desvios de atenção, como demonstra a Figura 9a seguir. 
Figura 9. Exemplo de Centro e Margem

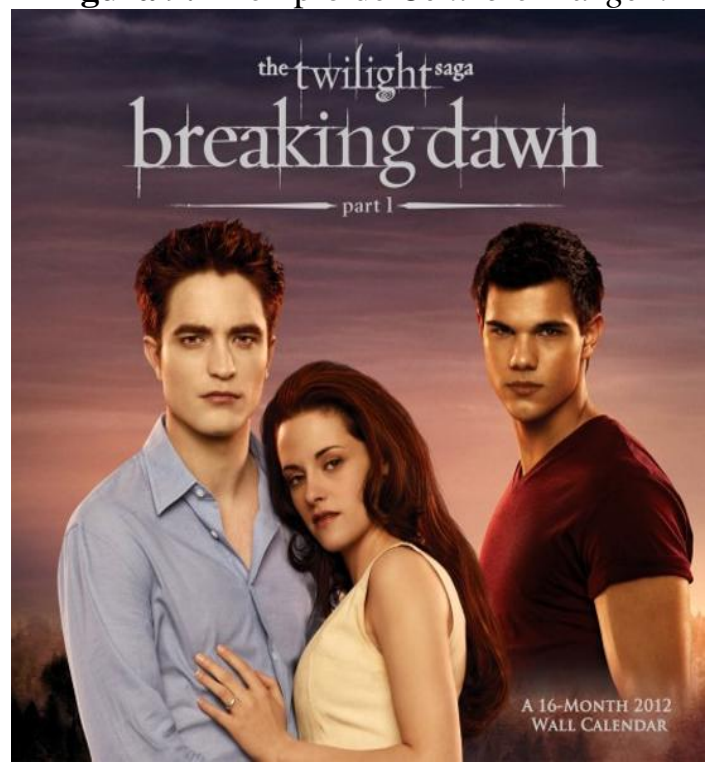

Fonte:<http://blog.telecine.globo.com/platb/sagacrepusculo/2011/07/04/novoposter-de-amanhecer $\geq$. Acesso em: 24 out. 2014

O cartaz apresentado demonstra a centralidade dos personagens principais (o casal), na trama do filme, e a lateralidade e subordinação do personagem antagonista, que se posiciona à direita da imagem. Trata-se, certamente, de indícios altamente significativos na compreensão e simbologia da trama.

\section{A multimodalidade nas aulas de português}

Avaliações em larga escala como o Programa Internacional de Avaliação de Estudantes (Pisa) e a Prova Brasil (que compõe o Sistema de Avaliação da Educação Básica) atestam que a proficiência leitora dos estudantes brasileiros está abaixo do nível recomendado.

Embora os motivos da baixa competência leitora sejam de mapeamento complexo e certamente envolvam razões políticas e socioeconômicas, acreditamos que entre as ações empreendidas pela 
escola na busca pela superação do problema precisa constar a ampliação tanto do conceito quanto da atividade de leitura.

Ampliar o conceito significa compreender a leitura como uma atividade sociocognitiva que ultrapassa a (de)codificação pela língua, alcançando a atividade de compreensão em sentido lato. Lemos expressões corporais e faciais, a posição das estrelas, a dinâmica do trânsito, cenários políticos e projeções econômicas, códigos de barras, titulações de experimentos científicos e uma gama quase infinita de imagens (com ou sem movimento), além de palavras. Apesar disso, a escola tradicional concede um poder quase totalitário à linguagem verbal, como se ela significasse sozinha, por si e em si mesma.

Dessa forma, precisamos conferir à multimodalidade um tratamento mais prosaico, considerando-a um modo natural e recorrente de interação linguageira contemporânea, não um "tópico do conteúdo" alheio aos sujeitos.

Por essa via, ampliar as atividades de leitura escolar significa oferecer aos aprendizes oportunidades de pensarem o mundo na proporção em que ele se apresenta: plural, multissemiótico e multifacetado. Se a escola forma cidadãos para o mundo e se os meios de expressão contemporâneos são multimodais, notadamente não há como se esquivar desse expediente de ensino.

É preciso, então, discutir quais as possibilidades de compreensão proporcionadas pelas cores, pelo tamanho e pela posição das letras, pela diagramação, pelo design, pelos elementos das imagens, pelos gestos, pelos ruídos, etc. Em linguagem, tudo significa, nada é gratuito.

É preciso também trabalhar com gêneros pouco usuais à escola, mas muito importantes no dia a dia das pessoas, como cartazes de filmes, publicidade, capas de revistas, infográficos, primeira página de jornais, discursos políticos orais, entre outros.

Embora charges e tirinhas sejam excelentes gêneros para se abordar a multimodalidade na escola, parece haver, em algumas instituições, um predomínio exagerado delas quando se fala em leitura multimodal. Diversificar os gêneros é ampliar a capacidade de reflexão dos estudantes e oferecer uma amostragem mais real das atividades de linguagem do mundo.

Por fim, frisamos que, apesar de priorizarmos, neste artigo, a atividade de leitura, não podemos perder de vista a importância do 
ensino de produção textual sob a égide da multimodalidade. $\mathrm{O}$ avanço tecnológico tem oferecido facilidades gráficas capazes de tornar a comunicação humana mais dinâmica, objetiva e persuasiva. É função da escola se apropriar desses recursos e oferecer meios instrutivos para sua utilização.

\section{Considerações finais}

Este artigo buscou apresentar a Teoria da Multimodalidade com base em um recorte capaz de proporcionar alguma segurança teórica a professores de português. Assim, apresentamos tanto influências basilares quanto categorias de análise, no intuito de ilustrar o que se pode fazer no campo da TM para ler textos compostos por linguagem verbal e não verbal.

Alertamos para o fato de que embora a TM seja um instrumental altamente relevante para pensar contribuições semânticas de imagens, a compreensão do modo visual ultrapassa as barreiras dessa teoria, uma vez que a vivência e a compreensão linguageira do professor pode - e deve - somar-se à teoria. Dizemos com isso que a intuição e a percepção do professor, aliadas ao estudo da GVD, tornam-se ferramentas indispensáveis, pois a teoria precisa ser vista mais como um farol (um guia) do que como uma âncora (uma limitação).

$\mathrm{Na}$ sala de aula, uma das principais tarefas do professor, no que tange à multimodalidade, é conscientizar seus alunos de que eles podem e devem refletir sobre os aspectos visuais do texto, ainda que ele não seja composto por imagens (pois todo texto é multimodal, a diagramação e a disposição das letras, por exemplo, compõem o aspecto visual do texto). Conseguir ampliar o conceito de leitura para além do significado das palavras, abarcando, em textos orais, por exemplo, a linguagem corporal, as expressões faciais, a cadência e a entonação, e no texto escrito aspectos como tamanho, cor e diagramação da fonte, é uma missão com alto teor de repercussão na expansão da competência leitora dos estudantes.

Por fim, defendemos que levar estudantes da Educação Básica a compreender que o aspecto não verbal contribui decisivamente para a produção de sentidos é um modo de fomentar a perspectiva crítica dos 
sujeitos - competência muito importante em tempos obscuros e instáveis como os que vivemos.

\section{Referências}

BEZERRA, F. A. S.; HEBERLE, V. M.; NASCIMENTO, R. G. do. Multiletramentos: iniciação à análise de imagens. Linguagem \& Ensino, Pelotas, v. 14, n. 2, p. 529-552, jul./dez. 2011. Disponível em: <revistas.ucpel.tche.br/index.php/rle/article/view/38/24>. Acesso em: 10 out. 2014.

DIONÍSIO, A. P. Gêneros textuais e multimodalidade. In: KARWOSKI, A. M.; GAYDECKZA, B.; BRITO, K. (Org.). Gêneros textuais: reflexões e ensino. 4. ed. São Paulo: Parábola, 2011. p. 137152.

PREDIGER, A.; KERSCH, D. F. Usos e desafios da multimodalidade no ensino de línguas. Signo, Santa Cruz do Sul, v. 38, n. 64, p. 209227, jan. 2013. Disponível em: <https://online.unisc.br/seer/index.php/signo/article/view/3419>. Acesso em: 25 out. 2014.

HALLIDAY, M. A. K. An introduction to functional grammar. 3. ed. London: H. Education, 2004.

ROJO, R. H. R. Pedagogia dos multiletramentos: diversidade cultural e de linguagens na escola. In: ROJO, R. H. R.; MOURA, E. (Org.). Multiletramentos na escola. São Paulo: Parábola Editorial, 2012. p. 1132.

VIEIRA, J. A.; SILVESTRE, C. Introdução à Multimodalidade: contribuições da Gramática Sistêmico-Funcional, Análise de Discurso Crítica e Semiótica Social. 1. ed. Brasília: JAV. Edit., 2014.

DIONÍSIO, A. P.; VASCOBCELOS, L. J.; SOUZA, M. M. Multimodalidades e leituras: funcionamento cognitivo, recursos semióticos e convenções visuais. Recife: Pipa Comunicação, 2014. 77 p. Disponível em: <http://pibidletras.com.br/serie-experimentando- 
Introdução à teoria da multimodalidade...

teorias/ET1-Multimodalidades-e-Leituras.pdf>. Acesso em: 15 fev. 2015.

KRESS, G.; VAN LEEUWEN, T. Reading images: the grammar of visual design. 2. ed. Nova York: Routledge, 2006.

SANTOS, Z. B. dos. As considerações da gramática do design visual para a constituição de textos multimodais. Interletras, Dourados, MS, v. 2, p. 2, 2010.

SIMÕES, A. C.; MACEDO, F. J. F. Todos têm um lado devassa, qual é o seu?: análise discursiva das publicidades da cerveja Devassa. Revista FACEVV, Vila Velha, ES, n. 10, p. 04-18, jan./jun. 2013. Disponível em: <http://facevv.cnec.br/wpcontent/uploads/sites/52/2015/10/TODOS-T\%C3\%8AM-UM-LADODEVASSA-QUAL-\%C3\%89-O-SEU-AN\%C3\%81LISE-

DISCURSIVA.pdf>. Acesso em: 10 set. 2014.

PETERMANN, J. A publicidade BomBril: o segredo do sucesso. 2006. 99 f. Dissertação (Mestrado em Letras) - Faculdade de Letras, Universidade Federal de Santa Maria, Santa Maria, 2006. Disponível em: https://repositorio.ufsm.br/handle/1/9757. Acesso em: 20 maio 2014.

PINHEIRO, V. S. Analisando significados de capas da revista Raça Brasil: um estudo de caso à luz da Semiótica Social. 2007. 135 f. Dissertação (Mestrado em Linguística) - Faculdade de Letras, Universidade Federal de Minas Gerais, Belo Horizonte, 2007. Disponível em: <http://www.bibliotecadigital.ufmg.br/dspace/handle/1843/ALDR73HHJU>. Acesso em: 21 jan. 2014.

Recebido em: 30/10/2018 Aceito em: 26/02/2019

Title: An introduction to Multimodality Theory: a panoramic approach for language teachers 